\title{
AÇÕES EMPREENDEDORAS E O PLANO NACIONAL DE EDUCAÇÃO EM MUNICÍPIOS SUL-MINEIROS
}

Lauriene Teixeira Santos ${ }^{1}$

Juliana De Oliveira Becheri ${ }^{2}$

Izadora Ribeiro E Garcia De Oliveira ${ }^{1}$

\footnotetext{
${ }^{1}$ Universidade Federal de Lavras / Departamento de Administração e Economia

2 Universidade Federal de Lavras
} 


\section{AÇÕES EMPREENDEDORAS E O PLANO NACIONAL DE EDUCAÇÃO EM MUNICÍPIOS SUL-MINEIROS}

Resumo: Considerando que o desenvolvimento de ações empreendedoras no setor público pode trazer diversos benefícios relacionados a otimização de processos e melhoria do serviço prestado, o presente artigo buscou conhecer as ações empreendedoras desenvolvidas na secretaria municipal da educação de dois municípios localizados no sul de Minas Gerais e compreender se essas influenciam no alcance das metas do Plano Nacional de Educação (PNE). A pesquisa se trata de um estudo qualitativo básico, que utilizou como técnica de coleta de dados realizou-se uma entrevista semi-estruturada com a secretária de educação de cada um dos dois municípios estudados. Os dados coletados foram analisados através da análise de conteúdo. Assim sendo, foi possível perceber que há ações desenvolvidas, nos dois municípios estudados, que contemplam quatro das metas do PNE. Contudo, percebeu-se também que as ações empreendedoras desenvolvidas, são diferentes em cada município, de acordo com as especificidades da realidade de cada um.

Palavras-chave: Empreendedorismo. Ações empreendedoras. Plano Nacional de Educação. Dificuldades.

\section{$1 \quad$ Introdução}

O empreendedorismo ao longo dos anos foi estudado por diversas óticas, destacandose a abordagem economicista e a abordagem comportamentalista. Respectivamente, entendese que a primeira está ligada ao entendimento sobre os resultados da atuação empreendedora que reflete nas economias de mercado, já a segunda, possui uma preocupação em compreender o sujeito empreendedor, bem como, suas habilidades e características (TONELLI; BRITO; ZAMBALDE, 2011). De acordo com Boava e Macedo (2006) a abordagem econômica costuma ganhar mais destaque, visto os interesses que possuem governo e sociedade.

Contudo, reduzir o estudo do empreendedorismo às áreas definidas como economia, psicologia ou administração faz com que se obtenha um olhar restrito da área de estudo. Para que se possa ter uma visão holística sobre o empreendedorismo, torna-se necessário que haja o entendimento de que a temática é própria do homem e, portanto, está presente em todas as esferas das atividades humanas, como na academia, nos esportes, na política e na vida cotidiana como um todo (BOAVA; MACEDO, 2006). Ao ir além da possibilidade de desenvolvimento de determinadas habilidades nos indivíduos, ou do foco nas condições ambientais que são impostas a eles, é possível entender que pessoas que nunca se imaginaram desenvolvedoras de iniciativas empreendedoras, podem se ver executando este papel (TONELLI; BRITO; ZAMBALDE, 2011).

Quando se trata especificamente do setor público, é possível perceber que há atualmente, uma maior cobrança para que haja uma melhor alocação dos recursos públicos, onde os objetivos sejam atingidos pautando-se por valores éticos e morais, alcançando uma melhoria da qualidade dos serviços prestados pela administração pública (BORGES; ROMANIELLO; BRITO, 2016; MONTEIRO et al., 2016). Para Monteiro et al. (2016), essa nova forma de percepção da administração pública fez com que o servidor público fosse 
considerado muitas vezes sem preparo e desqualificado para atender a essas novas demandas sociais.

Assim, manter o foco na ação empreendedora ajuda a compreender esses novos requisitos no âmbito da gestão pública, já que a ação empreendedora acaba por se tornar um elemento central que proporciona o desenvolvimento das organizações públicas, onde, neste contexto o agir empreendedor faz muita diferença nos resultados alcançados (MONTEIRO et al., 2016). Entretanto, a visão empreendedora no setor público necessita de um cuidado especial, uma vez que este é pautado por princípios burocráticos, os quais dão garantias de legitimidade para as atividades que são executadas, não sendo possível desvincular o setor público dessa característica tão primária (VALADARES et al., 2012). Por esse motivo, na visão dos autores citados, não se deve ter uma expectativa muito exagerada quando se trata do empreendedorismo público.

Ainda que não seja um setor considerado encorajador para o desenvolvimento de ações empreendedoras, estas não são impossíveis de ocorrer. Se tratando especificamente de instituições voltadas para o ensino, estas podem apresentar ações empreendedoras, voltadas para o cumprimento do Plano Nacional de Educação (PNE). O PNE, que atualmente compreende o período de 2014 até 2024, foi instituído pela Lei ${ }^{\circ} 13.005$, de 25 de junho de 2014 onde se estabelece diretrizes, metas e estratégias para a política educacional brasileira (INEP, 2017). É constituído por vinte metas que dão destaque para a garantia do direito à educação com qualidade, assegurando o acesso a universalização do ensino obrigatório e a ampliação das oportunidades educacionais, a redução das desigualdades, a valorização da diversidade e a valorização dos profissionais de educação (INEP, 2017).

Neste sentido, se torna interessante conhecer de que formas as metas estabelecidas pelo Plano Nacional de Educação, vem sendo cumpridas, e se há o desenvolvimento de ações empreendedoras por parte das Secretarias de Educação Municipais, para atender o que é proposto pelas metas. Acredita-se que o desenvolvimento de ações empreendedoras, com esse intuito, tem muito a privilegiar o aperfeiçoamento do serviço público prestado, atendendo aos usuários com excelência. Além disso, caso sejam encontradas ações empreendedoras nas Secretarias de Educação estudadas, estas podem servir de inspiração e modelo, para que outras Secretarias considerem diferentes formas de corresponderem ao que é proposto no PNE.

Dessa forma, e considerando as possibilidades que as ações empreendedoras podem trazer para o setor público, ainda que este seja muitas vezes enrijecido com relação a inovações chega-se ao seguinte questionamento: quais são as ações empreendedoras desenvolvidas na secretaria municipal da educação de dois municípios localizados no sul de Minas Gerais e como elas influenciam no alcance das metas do Plano Nacional de Educação?

Buscando responder a este questionamento, tem-se como objetivo geral deste estudo: conhecer as ações empreendedoras desenvolvidas na secretaria municipal da educação de dois municípios localizados no sul de Minas Gerais e compreender se estas influenciam no alcance das metas do Plano Nacional de Educação. Especificamente objetiva-se: (1) identificar as ações empreendedoras em cada um dos municípios; (2) apontar possíveis dificuldades de implementação de ações empreendedoras. 


\section{Fundamentação teórica}

Buscando contextualizar a temática que norteia o presente artigo, a fundamentação teórica apresenta os seguintes tópicos: Empreendedorismo e ação empreendedora; e, A ação empreendedora e o setor público.

\subsection{Empreendedorismo e ação empreendedora}

Ao longo da história, ocorreram - e ainda ocorrem - diversas tentativas de definir o conceito de empreendedorismo e da figura do empreendedor, bem como de realizar o delineamento de qual seria seu papel na sociedade (COSTA; BARROS; MARTINS, 2012). Uma vez que o empreendedorismo, esteve por muito tempo, vinculado somente a figura do empreendedor, é possível entender o estímulo para a definição e compreensão de ambos os conceitos. Assim, dentre as várias definições encontradas, algumas são influenciadas pelos economistas, outras pelos comportamentalistas, e ainda existem definições que não se enquadram em nenhum dos dois contextos (GOMES; LIMA; CAPPELLE, 2013).

Cantillon, Jean Baptiste Say e Joseph Schumpeter e, tinha como interesse central conhecer qual era o papel do empreendedor e qual sua atuação na economia, entendendo que este se

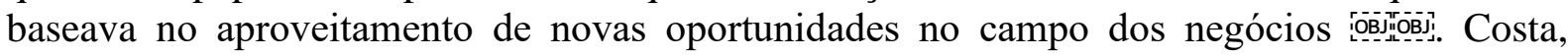
Barros e Martins (2012) acrescentam que a abordagem econômica buscava relacionar o empreendedorismo com as ideias de inovação, risco calculado e desenvolvimento, dentro de um contexto econômico representado pelas forças livres do mercado e da concorrência.

Por sua vez, acredita-se que a teoria comportamental teve seus primeiros delineamentos com Max Weber, porém o autor que realmente deu início à contribuição para essa área foi David C. McClelland, onde buscou-se conhecer o empreendedorismo pela lente do comportamento humano e suas motivações (BAGGIO; BAGGIO, 2014). Há uma ênfase aos "aspectos subjetivos do indivíduo, de modo, inclusive, a traçar o que seria um "perfil psicológico" ou "comportamental" do empreendedor" (GOMES; LIMA; CAPPELLE, 2013, p. 211). Carmargo, Cunha e Bulgacov (2008) também apontam para o fato de haver uma busca por delinear a personalidade e as características individuais, centrando então, os estudos no indivíduo.

Em resumo, os economistas associam a figura do empreendedor com o conceito de inovação, ao passo que os comportamentalistas possuem um foco nos aspectos criativos e intuitivos (FILION, 1999). Assim, para os primeiros teóricos economistas e para os comportamentalistas, o foco de estudo se encontrava no sujeito da ação empreendedora como marca inicial para o estudo do empreendedorismo como um todo (GOMES; LIMA; CAPPELLE, 2013). A ênfase no indivíduo direciona o estudo do empreendedorismo para o seu protagonista, o empreendedor, buscando observar e identificar as causas, os efeitos e as motivações relacionadas ao fenômeno empreendedor (OLIVEIRA et al., 2016).

Em 1985, Drucker passa a observar as capacidades de gestão e a postura empreendedora, nesse mesmo sentido, Gartner (1985) indica que é interessante estudar os empreendedores no processo de criação das organizações, estudos esses, característicos da Era Gerencial, como afirmam Franco e Gouvêa (2016). As abordagens tratadas aqui, são apenas algumas das várias que abordam o empreendedorismo. Como o presente artigo não busca uma discussão aprofundada entre todas essas abordagens, optou-se por apresentar apenas um 
pequeno contexto, para que fosse possível compreender a complexidade do campo empreendedorismo. Cabe destacar ainda, que tais fases histórico-científicas estão relacionadas e não são facilmente delimitadas ao longo do tempo (BARON; SHANE, 2007).

Assim, é possível perceber que as definições e representações de empreendedorismo, estiveram por muito tempo concentradas em aspectos que são facilmente mensuráveis, sendo pouco explorado as ligações entre os elementos que impulsionam o ato de empreender, ou seja, "os modos de pensar que levam à ação empreendedora" (SCHAEFER; MINELLO, 2017, p. 506). Atualmente, ao definir o empreendedorismo os autores têm elaborado seus conceitos fazendo uma relação com o termo "ação empreendedora", ou como sendo este um processo ininterrupto que só se faz possível através das atividades de seu ator principal (GOMES et al., 2014).

De acordo com Camargo, Cunha e Bulgacov (2008) ao ser considerado por Schumpeter que o ser empreendedor não é uma condição permanente, onde o indivíduo deixa de ser empreendedor a partir do momento que a inovação introduzida por ele, passa a ser administrada como uma mera rotina, é possível voltar o olhar para a ação empreendedora, sendo esta o resultado das relações entre o indivíduo com agentes e instituições em seu contexto social e histórico. Assim, a visão de Schumpeter deixou de ser focada apenas no indivíduo empreendedor, visto como um herói, um destruidor criativo, para entender que o papel da inovação transcendia o próprio indivíduo, passando a admitir a importância das equipes e, posteriormente, o papel das instituições para a inovação (GOMES; LIMA; CAPPELLE, 2013).

As recentes perspectivas a respeito do estudo do empreendedorismo, sugerem que o foco deve ser na reconstrução do processo no qual ocorre a ação empreendedora, compreendendo quais elementos orientam essa ação (MOCELIN; AZAMBUJA, 2017). Para os autores, esse processo é guiado pelas competências e habilidades que os indivíduos adquirem para reconhecerem oportunidades. Contrapondo aos diversos estudos que buscam entender os motivos pelos quais os indivíduos empreendedores agem de forma diferente. Quando se trata da ação empreendedora o principal interesse é saber se ela ocorre e como ocorre (MCMULLEN; SHEPHERD, 2006). Boava e Macedo (2009) destacam que não há ação empreendedora que dure eternamente, já que esta depende de um momento histórico, que é sempre provisório, temporário. A ação empreendedora estabelece uma trajetória de participação, conectando o passado ao futuro e, ao mesmo tempo criando uma relação de influência do individual para o coletivo e vice-versa (BULGACOV et al., 2017).

\footnotetext{
As ações empreendedoras podem ser conceituadas como um fenômeno observável em organizações empresariais ou não empresariais, sendo identificadas na consideração ou construção de oportunidades, bem como associadas a processos de transformação em relações internas e externas mantidas pelos agentes sociais nelas presentes e na promoção da consolidação dessas transformações nas relações das organizações com seus stakeholders e com o ambiente global (ANDRADE; LIMA; BORGES, 2014, p. 2).
}

Para que se realize uma ação empreendedora, é necessário ter criatividade e inovar, lidando com circunstâncias sociais e econômicas, mas tendo em mente os resultados esperados (SPEDALE; WATSON, 2014). Os autores ainda pontuam que ao tratar de ação empreendedora, o estudo de empreendedorismo vai além da criação de novos 
empreendimentos e da formação de novas organizações, criando uma abrangência bem mais ampla para o estudo do tema. A ação empreendedora se caracteriza então, como o elemento central do empreendedorismo e, é possível observar as manifestações deste por intermédio das oportunidades e das transformações que ocorrem dentro de uma organização (ANDRADE; LIMA; BORGES, 2014).

\subsection{A ação empreendedora e o setor público}

Para a modernização da administração do Estado brasileiro, os governos, realizaram reformas administrativas que possuíam como premissa a melhora do desempenho do setor público (VALADARES et al., 2012). Assim, dois modelos organizacionais foram apresentados: a administração pública gerencial e o governo empreendedor, onde ambos incorporam indicações de como melhorar a efetividade da gestão nas organizações públicas (SECCHI, 2009).

A visão do empreendedorismo é primordialmente associada e restrita ao setor privado, como sendo uma característica indissociável de uma organização que almeja obter sucesso (BORGES; ROMANIELLO; BRITO, 2016; VALADARES; EMMENDOERFER, 2015). No entanto, nos últimos anos, tem ocorrido uma introdução do empreendedorismo no setor público (BORGES; ROMANIELLO; BRITO, 2016; NACIMENTO, 2018; FERREIRA; ANDRADE; NASCIMENTO, 2018), como uma forma de criar valor para os cidadãos (VALADARES; EMMENDOERFER, 2015), visto que as instituições do setor público são, por regra, sem fins lucrativos, e devem buscar atender de forma satisfatória os interesses públicos, demandando portanto, novas configurações de gestão (LIMA et al., 2018).

Há o uso cada vez mais recorrente de práticas de Gestão do Conhecimento na Administração Pública que, em conjunto com a crescente preocupação de líderes em melhorar os processos de forma empreendedora e colaborativa, fazem com que a inovação esteja presente na Administração Pública (ANGELIS, 2010). Acredita-se que isso tem ocorrido, visto que as premissas tradicionais da Gestão Pública e as antigas formas de governar têm se mostrados ineficientes, deixando de apresentar efetividade nos serviços públicos ofertados (BORGES; ROMANIELLO; BRITO, 2016). Assim, de acordo com os autores, o empreendedorismo surge como uma forma de se realizar melhorias de modo inovador. Para Valadares e Emmendoerfer (2015) este é um processo de modernização que tem influenciado noções comportamentais e gerencias.

Devido a um alto grau de burocratização no setor público, entende-se que este é um contexto que inibe o desenvolvimento de uma cultura empreendedora baseada em inovação, autonomia e flexibilidade (VALADARES; EMMENDOERFER, 2015). Os autores apontam então que, para o setor público, o empreendedorismo se torna um grande desafio, visto que o contexto desse setor possuí peculiaridades diferentes do setor privado. Ao mesmo tempo, se torna cada vez mais difícil ignorar que o empreendedorismo tem muito a contribuir para um melhor desempenho do setor público no Brasil (BORGES; ROMANIELLO; BRITO, 2016; NACIMENTO, 2018; FERREIRA; ANDRADE; NASCIMENTO, 2018; OSBORNE; GAEBLER, 1992).

De acordo com Angelis (2010) uma vez que as organizações públicas são mais vulneráveis a sofrerem interferência do poder político, dentre suas principais características se encontram a burocracia, o autoritarismo centralizado, o paternalismo, a descontinuidade e a 
ingerência política. Essas características por sua vez, influenciam diretamente no modo como as pessoas agem dentro dessas organizações, onde é possível observar um apego às regras e rotinas, a supervalorização da hierarquia, o paternalismo nas relações e o apego ao poder (ANGELIS, 2010). Dessa forma, devido as diversas especificidades que o setor público apresenta, a aplicação dos tópicos relacionados ao empreendedorismo não pode ser simplesmente implementada. É necessário realizar uma prévia análise do ambiente organizacional, estudando suas características, para que estas sejam empregadas de forma a favorecer a implementação de ações empreendedoras (BORGES; ROMANIELLO; BRITO, 2016).

Outro ponto a ser considerado é a ética dos valores, que é um conjunto de princípios norteadores da conduta dos indivíduos (SOUSA; PAIVA JUNIOR; LIRA, 2010). Neste aspecto é necessário considerar que o ambiente público, em grande parte das vezes, sofre com trâmites burocráticos, justamente para que se evite deliberações que tenham a possibilidade de serem consideradas como atos ilegais ou corruptos (SOUSA; PAIVA JUNIOR, 2010). Para os autores a ética dos valores impulsiona a ação empreendedora no setor público.

Assim, de acordo com Sousa e Paiva Junior (2010), ao realizar ações empreendedoras que sejam pautadas pela ética dos valores, encontra-se uma tendência benéfica para a instituição, por aumentar sua credibilidade junto aos parceiros, o que culmina no fortalecimento da imagem da instituição. Acredita-se que o empreendedorismo no setor público pode gerar impacto no ambiente externo, como mídia, sociedade, outros governos, dentre outros, onde a novidade gerada pode projetar positivamente, a imagem da organização e de seu governante (VALADARES et al., 2012).

Segundo Borges, Romaniello e Brito (2016, p. 90) o empreendedorismo no setor público pode ser entendido como uma "ação capaz de fazer com que as organizações públicas se tornem mais inovadoras, proativas e que tomem decisões conscientes". Para Souza e Paiva Junior (2010) a ação empreendedora no setor público só se torna possível a partir do impulso do indivíduo empreendedor, que através de seus esforços age com consequências políticas, econômicas e culturais. Contudo, Valadares e Emmendoerfer (2015) destacam que é necessário haver um cuidado específico com quem promove as ações empreendedoras no setor público, pois, diversas vezes, estes indivíduos buscam o alcance de resultados pessoais em detrimento dos resultados públicos, ainda que em seus discursos esteja sempre presente e enfatizado o compromisso com a sociedade.

A ação empreendedora no setor público pode também estar relacionada com o reconhecimento de oportunidades relacionadas à percepção da potencialidade de novos recursos ou lucros como resultado da criação de um empreendimento ou melhoria de algum processo já existente (SOUSA; PAIVA JUNIOR, 2010). Para os autores, essa afirmação vai de encontro ao pensamento schumpeteriano, que apresenta a expressão "novas combinações" identificando a possibilidade de criar novos produtos oriundos de combinação com outros préexistentes. Uma vez que as organizações públicas incorporam os preceitos do empreendedorismo, e desenvolvem uma orientação voltada para tal, elas se tornam aptas a promoverem uma cultura de mudança (VALADARES; EMMENDOERFER, 2015).

O empreendedorismo no setor público se dá através do diálogo, pela facilitação de processos, pelo envolvimento dos gestores com as redes, buscando sempre a eficiência e o desenvolvimento de ações coletivas, criando valor aos processos que, uma vez que são 
realizados de forma empreendedora, atingem resultados além dos esperados (NASCIMENTO, 2018). Borges, Romaniello e Brito (2016) consideram que o ambiente público pressupõe coletividade, logo se tornaria inviável desenvolver ações empreendedoras de forma isolada, devendo estas envolver os colaboradores da organização. Entende-se então que é necessário o incentivo da própria organização pública, para que haja o implemento de ações empreendedoras e para que estas obtenham sucesso nos seus objetivos.

\section{$3 \quad$ Procedimentos metodológicos}

A pesquisa se trata de um estudo qualitativo básico. Optou-se pela abordagem qualitativa, uma vez que se buscou conhecer de forma aprofundada duas secretarias de educação em cidades sul-mineiras com relação as ações empreendedoras desenvolvidas. Segundo Vieira (2006, p.15) a abordagem qualitativa atribui grande importância a "descrição detalhada dos fenômenos e dos elementos que o envolvem, aos depoimentos dos atores sociais envolvidos, aos discursos, aos significados e aos contextos".

Como técnica de coleta de dados optou-se pela entrevista semi-estruturada, pois jugouse que esta seria a técnica mais adequada para abranger o assunto de uma forma mais aprofundada, dando a oportunidade para os atores envolvidos discorrerem sobre as situações por eles vividas e desenvolvidas. Considerou-se também, que através dos dados coletados nas entrevistas seria possível enriquecer a fase de tratamento dos dados, com o intuito principal de responder aos objetivos propostos.

As entrevistas são provenientes de um projeto financiado pela Fundação de Amparo à Pesquisa do Estado de Minas Gerais (FAPEMIG) e denominado Ações Empreendedoras dos Dirigentes Públicos e Municipais de Regiões do Sul de Minas Gerais, sendo que este projeto teve início no ano de 2017. Assim sendo, as entrevistas foram realizadas com as Secretárias de Educação dos municípios de Ijací e Carrancas, entre os meses de Fevereiro e Março do ano de 2018, e cada entrevista durou em média uma hora e trinta minutos.

O roteiro de entrevista contou com dez tópicos para compreender as ações desenvolvidas para atender ao Plano Nacional de Educação. Cada tópico possuía um conjunto de perguntas (no máximo quatro) que levassem a compreensão do que era feito em prol do atendimento das metas do PNE.

Para a análise dos dados utilizou-se a técnica de análise de conteúdo. Bardin define a análise de conteúdo como:

Um conjunto de técnicas de análise das comunicações visando obter, por procedimentos, sistemáticos e objetivos de descrição do conteúdo das mensagens, indicadores (quantitativos ou não) que permitam a inferência de conhecimentos relativos às condições de produção/recepção (variáveis inferidas) destas mensagens (BARDIN, 1977, p. 42).

$\mathrm{Na}$ fase de pré-análise realizou-se a leitura das duas entrevistas transcritas buscando obter um maior contato com os dados coletados, afim de começar a identificar as ações empreendedoras desenvolvidas e possíveis dificuldades. Na fase de exploração do material, realizou-se a criação de duas categorias (ações empreendedoras identificadas em cada uma dos municípios e dificuldades encontradas na implementação de ações empreendedoras), conforme aos objetivos propostos, dentro das quais os dados foram classificados, realizando- 
se a análise temática. Para isso, efetuou-se novamente uma leitura das entrevistas, buscando observar trechos que correspondessem as categorias criadas. Ressalta-se que as todas as categorias emergiram dos dados, já que as ações empreendedoras realizadas poderiam ser as mais diversas. Por fim, foi feito o tratamento dos resultados obtidos, onde a partir da análise temática, fez-se a interpretação dos dados e por conseguinte, respondeu-se aos objetivos propostos.

\title{
$4 \quad$ Resultados e discussão
}

A presente seção está dividida nos seguintes tópicos: ações empreendedoras e dificuldades na implementação de ações empreendedoras.

\subsection{Ações empreendedoras}

Identificou-se em um primeiro momento ações realizadas buscando inserir os pais nas atividades escolares, bem como a comunidade como um todo. Sendo que ações voltadas para esses objetivos vão de encontro a meta dezenove do PNE, que dispõe que as escolas devem assegurar a efetivação da gestão democrática da educação, associada à consulta pública pela comunidade escolar (MEC/SASE, 2014). Percebeu-se que o município de Carrancas desenvolve mais ações nesse sentido, onde, na educação infantil são realizadas oficinas e os pais são convidados a participar. Os professores da escola criaram grupos de WhatsApp das suas turmas, onde os pais se sentem à vontade para dar opiniões e ficam mais próximos das atividades que acontecem no ambiente escolar. Nas aulas que possuem alguma atividade diferente são realizadas transmissões ao vivo, para que os pais que não conseguem estar presente possam acompanhar de alguma forma; as transmissões são feitas pela rede social Facebook, facilitando a interação dos pais com as aulas.

Ainda relacionado ao município de Carrancas e a meta dezenove, as ações e eventos desenvolvidos pela Secretaria de Educação são divulgadas através de uma página oficial no Facebook, chamada Educação Municipal de Carrancas, buscando uma maior interação da comunidade como um todo.

\begin{abstract}
“[...] acabei de postar um convite pra Conferência Municipal de Educação, e já teve compartilhamento, as pessoas compartilhando nas páginas delas e algumas pessoas comentando, e eu acho que surte efeito sim. Igual, nós fizemos uma aula dia 22 de março relacionado ao dia da água, onde participaram os alunos do quinto ano com uma aula fora da escola. Onde foi a aula? Na nascente de água que faz a captação da água para o uso aqui na zona urbana e a gente divulgou também a aula online, os pais participaram parabenizando. Então assim, algumas pessoas já vendo isso já começam a conhecer melhor" (CARRANCAS, p. 5).
\end{abstract}

No município de Ijací, são realizações reuniões periódicas e bimestrais com os pais e, quando se torna necessário são realizadas visitas ativas. É realizada também uma reunião geral, separada pelas séries, visando compartilhar o planejamento anual e enfocando a importância dos pais e da família nas atividades escolares. A secretária acredita que depois de ser adotado um novo sistema de ensino, os pais têm se envolvido mais. 
[...] “depois das apostilas eu já vi um crescimento maior, porque quando tem dúvidas os pais tão vindo aqui pra saber, pra tirar, sanar as dúvidas, principalmente procurando mais a biblioteca, porque eles estão participando junto com os filhos. E isso que é interessante" (IJACI, p. 5).

Ainda são desenvolvidos no município de Ijací um projeto chamado Semana do Bebê, onde há o acompanhamento das gestantes, durante uma semana. E está em desenvolvimento, um projeto chamado Mão Certa, que vai conscientizar as famílias sobre a violência doméstica e sexual contra crianças e adolescentes.

É possível perceber que uma diferença entre as ações desenvolvidas em prol de atender a meta dezenove do PNE, é que o município de Carrancas voltou seus esforços para a adesão de meios tecnológicos para obter uma melhor comunicação e participação com a comunidade como um todo e com os pais. Já o município de Ijací, trabalha com métodos mais tradicionais, sendo orientado principalmente, pela realização de reuniões e de conscientizações.

Foi possível identificar no município de Carrancas a criação de projetos educacionais, como o Projeto de Educação Patrimonial, visando dar visibilidade a bens tombados do município, bem como o resgate de festividades culturais locais, onde em cada ano a atenção é voltada para algum patrimônio ou festividade em especial. Há também o desenvolvimento do Projeto Meninos de Carrancas, que consiste em oferecer aulas de música no contra-turno para os alunos, focando na parte instrumental, já que a parte de canto é oferecida no turno normal. Os alunos participantes desse projeto fazem apresentações em festividades dos municípios da região.

[...] "eu quero instituir em lei, eu quero fazer esse projeto virar um projeto de lei, por quê? Porque se eu tiver um projeto de lei, o respaldo pra sair com os alunos pra onde eu quiser, eu vou ter condições financeiras de bancar um lanche numa viagem, todo o custo" (CARRANCAS, p. 9).

Ainda relacionado ao município de Carrancas, foi criado também um grupo chamado Catira Mirim, onde é ensinada a catira, uma modalidade de dança, para os alunos. A oferta de contra-turno, vai de encontro ao que é proposto pela meta seis do PNE, que dispõe que as escolas devem oferecer educação em tempo integral em, no mínimo, cinquenta por centro das escolas públicas, atendendo no mínimo, vinte e cinco por centro dos alunos da educação básica (MEC/SASE, 2014). Por outro lado, no município de Ijací não há atividades ofertadas no contra-turno.

Assim, é possível perceber, que o empreendedorismo no setor público tem a possibilidade de gerar impacto no ambiente externo a ele, como na mídia, na sociedade, em outros governos, dentre outros (VALADARES et al., 2012). Além disso, de acordo com os autores, a novidade gerada pode projetar positivamente a imagem da organização. Sousa e Paiva Junior (2010), também corroboram com esse posicionamento, ao apresentarem que uma vez que as ações empreendedoras ocorram pautadas pela ética, há um aumento da credibilidade da instituição frente aos parceiros, culminando no fortalecimento da imagem institucional.

Com relação ao atendimento da meta cinco do PNE, que busca garantir que os alunos do ensino fundamental concluam esta etapa com a idade recomendada (MEC/SASE, 2014), o 
município de Carrancas oferece um atendimento particular para os alunos que precisam de uma assistência, buscando sanar uma dificuldade do município com a recuperação paralela. Assim, são mantidas duas professoras fora da sala de aula para atender no máximo de três alunos por vez, realizando um rodízio entre as turmas, para que todas possam ser atendidas. A secretária acredita que os resultados são positivos:

[...] vou medir com o IDEB, mas no final do ano agora que os professores vão relatar pra mim como foi a experiência. Mas eu vi que a experiência foi boa, por quê? Porque eu coloquei as supervisoras para acompanhar o trabalho delas também [...] Então elas estão sendo tão cobradas quanto uma professora regente, então elas tem que preencher as fichas individuais, tem que preencher os relatórios, tem que demonstrar o que foi feito de diferente com cada aluno, no que que ele avançou, no que que ele não avançou. E à medida que o aluno conseguiu avançar bem ele é trocado, aí a gente pega um outro aluno que precisa de mais assistência (CARRANCAS, p. 14).

Nesse sentido, o município de Ijací adotou uma nova metodologia de ensino, realizando uma parceria com a Positivo, com o objetivo principal de realizar uma educação de forma sequencial, visando obter um maior acompanhamento da aprendizagem dos alunos.

[...] verifiquei algumas situações, em que eu vi que alguns professores já trabalhavam assim, usavam aqueles métodos bem antigos e as vezes planos de aula que já nem dá pra usar mais [...] A prioridade (na escolha) é porque ia ter uma sequência, desde a creche até o ensino fundamental, para não ser picado (IJACÍ, p. 2).

Percebe-se que os métodos adotados por cada município se deram de forma diferente, no município de Carrancas, por exemplo, as ações foram desenvolvidas de forma mais pontual, buscando sanar as dificuldades de cada aluno de forma particular. Já no município de Ijací houve uma reformulação completa da metodologia de ensino adotada, afetando desde a creche até o ensino fundamental. Pode-se dizer que a ação desenvolvida por Ijací, atende também a meta dois do PNE que busca a alfabetização de todas as crianças até o terceiro ano do ensino fundamental (MEC/SASE, 2014).

Dessa forma, entende-se que a ação empreendedora no setor público está relacionada, dentre outros aspectos, com a percepção da potencialidade de novos recursos resultantes da criação de um empreendimento ou melhoria de algum processo já existente (SOUSA; PAIVA JUNIOR, 2010).

Relacionado a meta número quatro, que dispõe que para a população de quatro a dezessete anos com deficiência, transtornos globais do desenvolvimento e altas habilidades ou superdotação, tenham acesso à educação básica e ao atendimento educacional especializado, preferencialmente na rede regular de ensino (MEC/SASE, 2014), ambos os municípios realizam parcerias com a APAE. De acordo com a secretária de Carrancas, existe uma menina com deficiência relacionada a mobilidade, que é atendida pela escola municipal, porém de acordo com a mesma:

[...] Temos um aluno que era atendido na escola regular na zona rural que fechou, finalizou. Ele foi detectado como um aluno de APAE, o CRAS dava atendimento nessa escola rural, conseguiu o BPC para esse aluno. E hoje esse aluno além de ter o 
BPC esse aluno faz regularmente na APAE. E a APAE é uma parceria nossa da educação com a assistência social e a saúde, porque a gente utiliza esses diversos meios para conseguir levar os alunos que a gente não tem condições de atender aqui na APAE. Eu acho que eles deveriam estar em uma escola regular sim, mas só que nós não temos um atendimento educacional especializado, nós não termos uma sala recurso, nosso município não tem uma psicóloga que possa atender ativamente, não temos os recursos que tem na escola da APAE [...] (CARRANCAS, p. 23).

No município de Ijací há um aluno que necessita do estudo de libras, um aluno autista e um aluno que necessita do auxílio de uma cadeira de rodas para se locomover. Ambos são atendidos pela rede municipal, com o auxílio de professores adicionais, para auxiliar o professor responsável pela turma. No entanto, há também aqueles que são direcionados para a APAE.

Nota-se então, que os municípios, na medida do possível atendem os alunos com deficiência através das escolas municipais, mas que ainda há empecilhos que os impedem de atender a todos eles, tornando-se então indispensável a parceira realizada com a APAE.

Por fim, identificou-se uma ação empreendedora no município de Ijací, que busca fornecer kits de uniformes para os alunos. Os kits contavam com um tênis, bermuda, calça comprida, agasalho, camiseta de educação física, camiseta de manga comprida, camisa de gola polo e uma camisa simples. Apesar de não se relacionar diretamente com nenhuma meta do PNE, acredita-se que uma ação nesse sentido pode auxiliar famílias com uma renda mais baixa, possibilitando então, uma igualdade entre os alunos.

$\mathrm{Na}$ Tabela 1 realiza-se uma síntese das ações empreendedoras identificadas, relacionadas as metas do PNE que estas atendem:

Tabela 1 - Ações empreendedoras relacionadas às metas do PNE

\begin{tabular}{|c|c|c|}
\hline PNE & Carrancas & Ijací \\
\hline $\begin{array}{c}\text { Meta } \\
19\end{array}$ & $\begin{array}{c}\text { Grupos de WhatsApp; transmissões ao vivo de } \\
\text { aulas com atividades fora do convencional; } \\
\text { divulgação dos eventos através de uma página } \\
\text { oficial }\end{array}$ & $\begin{array}{c}\text { Visita ativa; reunião geral, divida conforme cada } \\
\text { série, compartilhando o planejamento anual; } \\
\text { projeto Semana do Bebê; projeto Mão Certa }\end{array}$ \\
\hline $\begin{array}{c}\text { Meta } \\
6\end{array}$ & $\begin{array}{c}\text { Projeto Meninos de Carrancas; Grupo Catira } \\
\text { Mirim }\end{array}$ & Não há atividades no contra-turno \\
\hline $\begin{array}{c}\text { Meta } \\
5\end{array}$ & $\begin{array}{c}\text { Atendimento particular para os alunos que } \\
\text { apresentem dificuldade }\end{array}$ & $\begin{array}{c}\text { Nova metodologia de ensino, em parceria com a } \\
\text { Positivo }\end{array}$ \\
\hline $\begin{array}{c}\text { Meta } \\
4\end{array}$ & Parceria com a APAE & Auxílio de professores adicionais; Parceria com a \\
APAE
\end{tabular}

Fonte: Elaborado pelas autoras (2019).

De acordo com a Tabela acima, é possível perceber que as ações empreendedoras identificas desenvolvidas correspondem as metas dezenove, seis, cinco e quatro do PNE. O Plano Nacional de Educação é composto por vinte metas, mas ressalta-se aqui, que o fato de as ações empreendedoras não contemplarem as vinte metas, não significa que estas não são atendidas pelas Secretarias de Educação estudadas. Estas podem ser atendidas através de outras formas, que não são a foco de estudo deste artigo.

A ação empreendedora estabelece uma trajetória de participação, criando uma relação de influência do individual para o coletivo e vice-versa (BULGACOV et al., 2017). Destaca- 
se também, que quando se mantêm o foco na ação empreendedora, é preciso compreender que estas não duram eternamente, uma vez que dependem do momento histórico, e este por sua vez é provisório e temporário (BOAVA; MACEDO, 2009).

\subsection{Dificuldades na implementação de ações empreendedoras}

O município de Carrancas oferece aulas de "reforço" para seus alunos, buscando atender e sanar as dificuldades destes. Contudo, foi identificada uma dificuldade referente a realização desta ação, relacionada ao turno em que seria ofertado esse "reforço". Inicialmente, o reforço era realizado no contra-turno, porém os alunos não estavam comparecendo, fazendo com que os professores ficassem com tempo ocioso. Dessa forma, foi necessário passar o reforço para o turno normal.

[...] foi frustrante porque a maioria dos alunos que precisavam não vinham, então assim a gente ficava com o nosso tempo ocioso, pra gente não ficar com o tempo ocioso a gente tinha que ir na sala de aula e pedir pro professor pra gente auxiliar aluno com dificuldade no turno, porque não funcionava o contra-turno [...] (CARRANCAS, p. 15).

Uma outra dificuldade encontrada no município de Carrancas, refere-se ao plano de carreira dos profissionais da educação. O plano de carreira atende a meta dezoito do Plano Nacional de Educação, que dispõe sobre a elaboração de um plano de carreira para os profissionais da educação básica e superior pública de todos os sistemas de ensino (MEC/SASE, 2014). Segundo relato a intenção era envolver todos os profissionais relacionados com o ambiente escolar no plano de carreira, visando a valorização de todos os profissionais. Contudo, a secretária percebeu que isso não seria possível de ser realizado ao se deparar com a legislação vigente, que determina a inclusão apenas de professores, supervisores, orientador e diretor no plano de carreira.

Considerando esse cenário, é possível apresentar o que é enfatizado por Valadares et al. (2012). Para os autores, os princípios burocráticos que pautam o setor público, dão garantia de legitimidade para as atividades executadas. Logo, como não há meios de desvincular o setor público dessa característica primária, a visão empreendedora nesse setor, necessita de um cuidado especial (VALADARES et al., 2012).

Por fim, uma última dificuldade percebida relacionada ao município de Carrancas está relacionada a divulgação de eventos pela página oficial no Facebook e a falta de comunicação interna, já que a secretária depende do repasse de informações dos diretores escolares, e nem sempre isso acontece.

Com relação ao município de Ijací foi encontrada certa resistência por parte dos professores, no que se refere a adesão do sistema educacional da Positivo e, para sanar essa dificuldade foram realizadas reuniões de treinamento.

[...] alguns professores já se adaptaram, outros não. Ainda está tendo um pouquinho de resistência, mas assim, dos cursos que nós já tivemos, que essa assessoria, já diminuiu bem né, então já tá uma aceitação melhor [...] (IJACÍ, p. 3). [...] Aí nós vimos as dificuldades e começamos a separar por etapas de ensino né, por exemplo, a educação infantil então faz os módulos, vamos reunir com os módulos junto com a 
educação infantil, e foi sequencial. E também, essa assessoria junto a positivo" (IJACI, p. 4).

É possível perceber aqui, que houve resistência diante das mudanças que estavam ocorrendo no sistema educacional. Segundo Angelis (2010) é possível observar, que dentro do setor público, as pessoas agem com um certo apego às regras e rotinas e ao paternalismo nas relações. Há também, segundo a autor, apego ao poder e a supervalorização da hierarquia.

Sobre o plano de carreira dos profissionais da educação, encontram-se dificuldades para executar o mesmo, por pendências de regularização do município. De acordo com a secretária, sem haver essa regularização primeiro, não é possível realizar uma captação de recursos. No entanto, segundo a mesma, desde de que tomou ciência dessas pendências, tem aos poucos, tentado resolver esse problema.

$\mathrm{Na}$ Tabela 2 destaca-se as dificuldades encontradas na implantação de ações empreendedoras, de acordo com cada município.

Tabela 2 - Dificuldades encontradas

\begin{tabular}{|c|c|}
\hline Carrancas & Ijací \\
\hline Turno em que as aulas de "reforço" seriam ofertadas & $\begin{array}{c}\text { Resistência, por parte dos professores, ao novo sistema } \\
\text { educacional }\end{array}$ \\
\hline Plano de carreira dos profissionais da educação & Plano de carreira dos profissionais da educação \\
\hline $\begin{array}{c}\text { Divulgação de eventos e falta de comunicação } \\
\text { interna }\end{array}$ & \\
\hline
\end{tabular}

Fonte: Elaborado pelas autoras (2019).

Percebe-se aqui, que ambos os municípios estudados enfrentam dificuldades relacionadas ao plano de carreira dos profissionais da educação. Contudo, conforme exposto, são dificuldades enfrentadas por motivos diferentes. Mas, cabe ressaltar que o cumprimento da meta dezoito do Plano Nacional de Educação, é um ponto destacado pelas secretárias como um gargalo, tanto nos municípios de Ijací quanto de Carrancas.

Assim, é possível perceber que ambos os municípios enfrentaram algum tipo de dificuldade na implantação de alguma ação empreendedora. Porém, é possível perceber também que ações foram e são desenvolvidas buscando sanar tais dificuldades.

\section{$5 \quad$ Considerações finais}

O presente artigo buscou conhecer as ações empreendedoras desenvolvidas na secretaria municipal da educação de dois municípios localizados no sul de Minas Gerais e compreender se estas influenciam no alcance das metas do Plano Nacional de Educação. Assim, foi possível perceber que há ações desenvolvidas nos dois municípios estudados que contemplam quatro das vinte metas do PNE. Contudo, percebeu-se também que as ações empreendedoras desenvolvidas, são diferentes em cada município, de acordo com as especificidades da realidade de cada um.

Com relação as dificuldades na implementação das ações empreendedoras, foi possível observar algumas semelhanças em ambos os municípios. Destaca-se aqui, a dificuldade em comum no atendimento da meta dezoito do PNE, voltada para o plano de carreira dos profissionais da educação, ainda que por razões diferentes. Contudo, é importante 
ressaltar que, nas demais dificuldades encontradas, ambos os municípios tem desenvolvido alternativas que pudessem contornar o problema encontrado.

Uma vez que se reconhece a relevância do desenvolvimento de ações empreendedoras no setor público, como forma de otimizar processos e como forma de melhoria do atendimento e dos serviços prestados, e a importância de se atender as metas estipuladas no Plano Nacional de Educação, o presente estudo possibilita um maior entendimento do que é desenvolvido a nível municipal, nesse sentido. Cabe destacar também, que através deste estudo é possível desmistificar a noção de que o setor público é completamente engessado, uma vez que é possível perceber, através dos estudos apresentados na construção da fundamentação teórica e dos casos de Ijací e Carrancas, que há iniciativas empreendedoras no setor público.

Como contribuições gerenciais o artigo apresenta ações empreendedoras que já estão sendo desenvolvidas pela secretaria de educação de dois municípios, buscando o atendimento do Plano Nacional de Educação. Assim, é possível que demais secretarias tomem conhecimento dessas ações, e possam se beneficiar, no sentido de realizar um benchmarking com ações que já vêm dando resultados em outros lugares. Como contribuições acadêmicas contribui-se com a discussão acerca da discussão envolvendo ações empreendedoras, retirando o foco do indivíduo empreendedor para dar atenção ao que de fato foi desenvolvido. Por fim, as contribuições sociais convergem no sentido de que, além do importante papel das instituições públicas, está também o papel de toda a sociedade, neste caso específico, dos pais e responsáveis, para a melhoria do ensino e cumprimento das metas do PNE.

Uma limitação presente no estudo, encontra-se no fato das entrevistas terem ocorrido apenas com as secretárias de educação dos municípios estudados. Ainda que as secretárias tenham conhecimento das ações desenvolvidas em prol do atendimento do PNE, seria interessante conhecer a percepção de outros atores associados a execução dessas ações. Assim, como estudos futuros, sugere-se que se contemple a percepção de demais pessoas envolvidas na ação empreendedora. Ainda se sugere que haja o desenvolvimento de estudos desse tipo em outros municípios, podendo abranger outros setores, buscando verificar se há a realização de ações empreendedoras na execução das atividades, realizando um mapeamento das ações desenvolvidas.

\section{Referências bibliográficas}

ANDRADE, D. M.; LIMA, J. B.de; BORGES, A. F. Ações Empreendedoras em Empresas Familiares : Um Estudo Sob a Ótica de Oportunidades , Inovação e Aprendizagem. VIII Encontro de Estudos em Empreendedorismo e Gestão de Pequenas Empresas,p. 1-17, 2014.

ANGELIS, C. T.de. A importância do poder especialista para o empreendedorismo na Administração Pública. Revista Gestão \& Tecnologia,v. 10, n. 1, p. 1-11, 2010.

BAGGiO, A. F.; BAGGiO, D. K. Empreendedorismo: Conceitos e Definições. Revista de empreendedorismo, inovação e tecnologia,v. 1, n. 1, p. 25-38, 2014.

BARDIN, L. Análise de conteúdo. Lisboa: Edições 70, 1977. 229 p.

BARON, R. A.; SHANE, S. A. Empreendedorismo: uma visão do processo. São Paulo: Thompson Learning, 2007.

BOAVA, D.L. T.; MACEDO, F. M. F. Estudo sobre a essência do empreendedorismo. XXX 
Encontro da ANPAD, p. 1-17, 2006.

BOAVA, D. L. T.; MACEDO, F. M. F. Esboço para uma teoria tridimensional do empreendedorismo. XXXIII Encontro da ANPAD, p. 1-15, 2009.

BORGES, D. A. H.; ROMANIELLO, M. M.; BRITO, M. J.de. Empreendedorismo No Setor Público: a Influência Das Características Organizacionais. Revista de Empreendedorismo e Gestão de Pequenas Empresas,v. 5, n. 1, p. 85, 2016.

BULGACOV, Y. L. M.; CARMARGO, D. de.; CUNHA, S. K. da.; MEZA, M. L.; SOUZA, R. M. B.; TOLFO, S. da R. Atividade empreendedora da mulher brasileira: Trabalho precário ou trabalho decente? Psicologia Argumento, v. 28, n. 63, p. 337-349, 2017.

CAMARGO, D.de; CUNHA, S. K.da; BULGACOV, Y. L. M. A psicologia de McClelland e a economia de Schumpeter no campo do empreendedorismo. Revista de Desenvolvimento Econômico,v. 10, n. 17, p. 111-120, 2008.

COSTA, A. M.da; BARROS, D. F.; MARTINS, P. E. M. A alavanca que move o mundo: o discurso da mídia de negócios sobre o capitalismo empreendedor. Cadernos EBAP,v. 10, p. 357-375, 2012.

DRUCKER, P. F. Innovation and entrepreneurship: practice and principles. New York: Harper \& Row, 1985.

FERREIRA, M. C.; ANDRADE, D. M.; NASCIMENTO, P. O. Ações empreendedoras: um estudo na secretaria de educação de um município sul mineiro. CASI, 2018.

FILION, L. J. Empreendedorimo. Revista de Administração, v. 34, n. 2, p. 05-28, 1999.

FRANCO, J. O. B.; GOUVÊA, J. B. A cronologia dos estudos sobre o empreendedorismo. Revista de Empreendedorismo e Gestão de Pequenas Empresas, v. 5, n. 3, p. 144-166, 2016.

GARTNER, W. B. A conceptual framework for describing the phenomenon of new venture creation. Academy of Management Review, v. 10, n. 4, p. 696-706, 1985.

GOMES, A. F.; LIMA, J. B. de; CAPPELLE, M. C. A. Do Empreendedorismo à noção de ações empreendedoras : reflexões teóricas. Revista Alcance, v. 20, p. 203-220, 2013.

GOMES, R. K.; BOTELHO, M.; FURTADO, L. P.; LAPOLLI, É. M. O empreendedorismo no mercado de cervejas artesanais: um estudo de caso. In: LAPOLLI, É. M.; FRANZONI, A. M. B.; LAPOLLI, J. (Orgs.). Ações empreendedoras. Florianópolis: Pandion, 2014.

INSTITUTO NACIONAL DE ESTUDOS E PESQUISAS EDUCACIONAIS ANÍSIO TEIXEIRA (INEP). 2017. Monitoramento do PNE. Disponível em: http://inep.gov.br/dados/monitoramento-do-pne. Acesso em: 05 Jun 2019.

LIMA, S. F. A.; TEIXEIRA, R. M.; DANTAS, C. F.; ALMEIDA, M. A. Empreendedorismo público e orientação empreendedora em instituições federais de ensino. Revista de Ciências da Administração,v. 20, n. 50, p. 44-60, 2018.

MATTOS, R.; VENCO, S. Sistema nacional de educação e plano nacional de educação: significado, controvérsias e perspectivas. Cadernos Cedes, v. 35, n. 97, p. 611-615, 2015.

MCMULLEN, J. S.; SHEPHERD, D. A. Entrepreneurial Action and the Role of Uncertainty in the Theory of the Entrepreneur. Academy of Management Review, v. 31, n. 1, p. 132-152, 2006.

MINISTÉRIO DA EDUCAÇÃO / SECRETARIA DE ARTICULAÇÃO COM OS SISTEMAS DE ENSINO (MEC/SASE). Planejando a próxima década: conhecendo as 20 metas no Plano nacional de Educação, 2014.

MOCELIN, D. G.; AZAMBUJA, L. R. Empreendedorismo intensivo em conhecimento: elementos para uma agenda de pesquisas sobre a ação empreendedora no Brasil. Sociologias, 
v. 19, n. 46, p. 30-75, 2017.

MONTEIRO, I. P.; OLIVEIRA, D. R. de.; VALADARES, J. L.; EMMENDOERFER, M. L. Comportamento empreendedor no setor público: análise comparada de dois presidentes do Brasil. REGEPE - Revista de Empreendedorismo e Gestão de Pequenas Empresas, v. 5, n. 2, p. 51-75, 2016.

NASCIMENTO, P. O. A ação empreendedora na gestão pública escolar. 2018. 119p. Dissertação (Mestrado Profissional em Administração Pública) - Universidade Federal de Lavras, Lavras, 2018.

OLIVEIRA, I. R.; CAMARGO, M. L.; FEIJÓ, M. R.; CAMPOS, D. C. de.; GOULART JÚNIOR, E. Empreendedorismo social, pós-modernidade e psicologia: compreendendo conceitos, atuações e contextos. Gerais : Revista Interinstitucional de Psicologia, v. 9, n. 2, p. 290 $311,2016$.

OSBORNE, D.; GAEBLER, T. Reinventando o Governo: como o espírito empreendedor está transformando o setor público. Brasília: Editora MH Comunicações, 1992.

SAVIANI, D. Sistema Nacional de Educação articulado ao Plano Nacional de Educação. Revista Brasileira de Educação, v. 15, n. 44, p. 380-392, 2010.

SCHAEFER, R.; MINELLO, I. F. Mentalidade Empreendedora: Do Modo de Pensar ao Modo de Agir do Indivíduo Empreendedor. REGEPE - Revista de Empreendedorismo e Gestão de Pequenas Empresas, v. 6, n. 3, p. 495-524, 2017.

SECCHI, L. Modelos organizacionais e reformas da administração pública. Revista de Administração Pública, [s. 1.], v. 43, n. 2, p. 347-369, 2009.

SOUSA, J. L.de; PAIVA JUNIOR, F. G. de. O Empreendedorismo no Setor Público: A Ação Empreendedora da Fundação Joaquim Nabuco. EnAPG - Encontro de Administração Pública e Governança, 2010.

SOUSA, J. L. de.; PAIVA JUNIOR, F. G. de.; LIRA, Z. B. Abordagem multidimensional do empreendedorismo no setor público: o caso da ação empreendedora da fundação Joaquim Nabuco. Revista Gestão e Planejamento, Salvador, v. 11, n. 2, p. 337-354, jul/dez. 2010.

SPEDALE, S.; WATSON, T. J. The emergence of entrepreneurial action: At the crossroads between institutional logics and individual life-orientation. International Small Business Journal, v. 32, n. 7, p. 759-776, 2014.

TONELLI, D. F.; BRITO, M. J.de; ZAMBALDE, A. L. Empreendedorismo na ótica da teoria ator-rede: explorando alternativa às perspectivas subjetivista e objetivista. Cadernos EBAPE, v. 9, n. Edição Especial, p. 586-603, 2011.

VALADARES, J. L.; EMMENDOERFER, M. L.; ALVES, R. C. M.; MORAIS, M. C. A. O Fenômeno do Empreendedorismo Público: Um Ensaio sobre a Aplicabilidade desse Construto na Administração Pública Brasileira. XXXVI Encontro da Anpad, p. 1-16, 2012.

VALADARES, J. L.; EMMENDOERFER, M.L. A incorporação do empreendedorismo no setor público: reflexões baseadas no contexto brasileiro. Revista de Ciências da Administração, v. 17, n. 1, p. 82-98, 2015.

VIEIRA, M. M. F. Por uma boa pesquisa (qualitativa) em administração. In: VIEIRA, M. M. F.; ZOUAIN, D. M. (Org.). Pesquisa qualitativa em administração. 2 ed. Rio de Janeiro: Editora FGV, 2006. p. 13-28. 